\title{
RESEARCH
}

Open Access

\section{Exploring the potential of using bioactive plant products in the management of Fusarium oxysporum f.sp. albedinis: the causal agent of Bayoud disease on date palm (Phoenix dactylifera L.)}

Eimad Dine Tariq Bouhlali ${ }^{1 *}$ (D, Mgal Derouich² ${ }^{2}$ Houria Ben-Amar ${ }^{1}$, Reda Meziani ${ }^{1}$ and Adil Essarioui ${ }^{1}$

\begin{abstract}
Background: "Bayoud" disease caused by Fusarium oxysporum f. sp. albedinis (Foa) poses a serious threat to date palm (Phoenix dactylifera L.) in Morocco. However, research studies performed to discover biological methods to control this disease remain limited. The present study has set objectives to determine antifungal activity of five plants extracts (Acacia cyanophylla, Cupressus atlantica, Eucalyptus torquata, Nerium oleander, and Schinus molle) against Foa and link this effect to their content in polyphenols and flavonoids as well as their antioxidant properties.
\end{abstract}

Results: Plant extracts showed significant differences $(p<0.05)$ regarding their antifungal activity. The extracts of $E$. torquata and C. atlantica showed the strongest antifungal effect resulting in the inhibition of mycelial growth, sporulation, and spore germination in a dose-dependent manner. In addition, there were significant differences among the examined plant extracts in respect to their total polyphenols (1.536-7.348 g GAE/100 g DW), flavonoids (0.986-5.759 g RE/100 g DW), and antioxidant properties measured by Trolox equivalent antioxidant capacity (TEAC) (7.47-38.97 mmol TE/100 g DW) and ferric-reducing antioxidant power (FRAP) assay (8.95-47.36 mmol TE/100 g DW). Moreover, the antifungal potential of plant extracts was found to be moderately to strongly correlated with their polyphenol and flavonoid contents as well as their antioxidant activity, implying that the effective inhibitory activity of these plant extracts is partly due to their richness in antioxidative secondary metabolites.

Conclusion: Our findings shed further light on plants as a-yet-untapped resource of bioactive compounds and constructed the foundation for the development of new biological approaches to best manage Bayoud disease.

Keywords: Plant extract, Antifungal compound, Bayoud, Phoenix dactylifera L

\footnotetext{
* Correspondence: bouhlali.eimad@gmail.com

${ }^{1}$ National Institute for Agricultural Research, Regional Center of Errachidia,

Errachidia, Morocco

Full list of author information is available at the end of the article
}

\section{Springer Open}

(c) The Author(s). 2020 Open Access This article is licensed under a Creative Commons Attribution 4.0 International License, which permits use, sharing, adaptation, distribution and reproduction in any medium or format, as long as you give appropriate credit to the original author(s) and the source, provide a link to the Creative Commons licence, and indicate if changes were made. The images or other third party material in this article are included in the article's Creative Commons licence, unless indicated otherwise in a credit line to the material. If material is not included in the article's Creative Commons licence and your intended use is not permitted by statutory regulation or exceeds the permitted use, you will need to obtain permission directly from the copyright holder. To view a copy of this licence, visit http://creativecommons.org/licenses/by/4.0/. 


\section{Background}

Date palm (Phoenix dactylifera L.) has long been a major fruit crop in the semi-arid regions of Southern Morocco [1]. In these areas, date production is an important source of food and income for local populations and plays key economic and environmental roles by creating a suitable microclimate for growing other food crops and protecting oases from silting and desertification [2]. Date palm in Morocco is grown over 48,000 ha of traditional and genetically diverse oases, and 20,000 ha of modern plantations cultivating commercial varieties [3]. While the practice of agroforestry-based production system in the former offers opportunities for sustainability, intensive production coupled with cultivar genetic uniformity increase vulnerability to diseases caused by plant pathogens.

"Bayoud" disease is the principal enemy of palm trees that puts at risk the future of the date industry in Morocco [4]. Bayoud is a tracheomycosis caused by the soil-borne fungal pathogen Foa. The parasite attacks palms through the roots and ends up colonizing the entire vascular system, leading to wilt and ultimately to date palm death [5]. Since its first appearance in Morocco in the late nineteenth century, the disease has spread throughout all date-producing areas in Morocco and part of Algeria, killing respectively more than 10 and 3 million palm trees in these countries [6]. In addition, this epidemic has wiped out a wide range of cultivars that were highly appreciated by growers, leading to an impoverishment in palm genetic diversity and a decrease in farmer's income [6]. Currently, genetic resistance is the only effective method to control the disease $[6,7]$. However, although many Bayoud-resistant varieties have been selected, most of commercial varieties, such as "Mejhool" and "Bouffegous", are highly sensitive and require intensive management against the pathogen. These varieties are principally cultivated in modern farms established not far from Bayoud-infested areas, which constitute a constant risk of its introduction into pathogen-free locations [8]. Thus, there is an urgent need for developing appropriate anticipative management strategies to best manage the disease.

Plants produce a broad spectrum of secondary metabolites, such as alkaloids, phenols, quinones, flavonoids, glycosides, saponins, tannins, and terpenoids [9]. The roles of these bioactive compounds include inducing plant defence system against pathogen attacks during which their concentration in plants depends on pathosystem and environmental conditions [10]. Previous studies have reported that plant-derived products from members of the genera Acacia, Cupressus, Eucalyptus, Nerium, and Schinus possess strong antifungal activities against a broad spectrum of plant pathogenic fungi [1014]. Species of these botanical groups are widely distributed worldwide, including date palm-growing areas in Morocco, which present a great potential for their use in the management of Bayoud disease. This could be possible by recycling plant pruning waste of bioactive species as a soil amendment material in palm plantations. The breakdown of plant debris in the soil may result in the release of antimicrobial compounds that would confer protection against infection of date palm roots by Foa.

In the perspective of developing bioactive soil amendments using selected plants, the aim of this study is to (i) investigate antifungal effects of aqueous extracts of 5 plant species (Acacia cyanophylla, Cupressus atlantica, Eucalyptus torquata, Nerium oleander, and Schinus molle) against Foa, (ii) to determine their richness in secondary metabolites (polyphenols and flavonoids), and (iii) to measure their antioxidant properties. This work contributes to constructing a more comprehensive understanding of the mechanisms by which plant compounds may affect Foa survival and development.

\section{Materials and methods}

\subsection{Plant material}

Plant pruning wastes (leaves, branches, twigs etc.) of Acacia cyanophylla (ID CRRAE 06/2020), Cupressus atlantica (ID CRRAE 07/2020), Eucalyptus torquata (ID CRRAE 08/2020), Nerium oleander (ID CRRAE 09/ 2020), and Schinus molle (ID CRRAE 10/2020) generated following green urban space management in Errachidia City (South-Eastern Morocco) were collected during October 2019 from public parks and gardens in the former city. The plant species were identified by Dr. Homrani Bakkali, a botanist in National Institute of Agricultural Research and the herbarium specimens for each plant species were prepared and deposited at the same institute. The collected plant material was air-dried under shade, ground to a powder using an electric grinder and stored at room temperature $\left(25{ }^{\circ} \mathrm{C}\right)$ in dark for further use.

\subsection{Preparation of polyphenol rich extracts}

Stock solutions $(10 \%, \mathrm{w} / \mathrm{v})$ of polyphenol rich extracts were prepared for each plant species using a modified method reported by Hmidani et al. [15]. Briefly, $30 \mathrm{~g}$ of plant fine powder were mixed with $300 \mathrm{~mL}$ of water at $50{ }^{\circ} \mathrm{C}$ using an orbital shaker-incubator during $6 \mathrm{~h}$. The mixture's filtrates were used to assess the antifungal activity, phenolic, and flavonoid contents, as well as antioxidant properties.

\subsection{Antifungal activity of plant extracts 2.3.1 Spore germination inhibition assay}

The ability of plant extracts to inhibit spore germination of Foa was examined using the method described by 
Bammou et al. [16]. Fractions of each extract's stock solution $(10 \%)$ were diluted down to $1 \%, 2 \%$ and $3 \%$. The resulting dilutions were used in the preparation of Potato dextrose agar (PDA) medium. For each plant extract and concentration, an aliquot of $100 \mu \mathrm{L}$ of Foa spore suspension adjusted to $10^{5}$ spores $/ \mathrm{mL}$ of sterile distilled water (using Malassez's hemocytometer) was spread onto the plates of the supplemented PDA medium. The number of spores germinating out of 50 counted was determined after $24 \mathrm{~h}$ of incubation at $25 \pm 2{ }^{\circ} \mathrm{C}$. A spore was considered germinating when the length of its germ tube was greater than its smallest diameter. Each treatment included five replicates and a negative control containing un-supplemented media. Using these counts, the percentage of spore germination inhibition by each plant extract was calculated:

Inhibition of spore germination $(\%)=\frac{(\mathrm{Nc}-\mathrm{Nt})}{\mathrm{Nc}} \times 100$

Where

Nc: number of germinating spores in the control

$\mathrm{Nt}$ : number of germinating spores in the treatment

\subsubsection{Mycelial growth inhibitory assay}

Mycelial growth inhibition of Foa by plant extracts was assessed using the method described by Sellam et al. [17] with slight modification. Five millimeters of mycelial discs from 7-day-old culture of Foa was transferred onto Petri dishes containing PDA medium supplemented with plant extracts as indicated above. Thereafter, the plates were incubated at $25 \pm 2{ }^{\circ} \mathrm{C}$ for 7 days. Mycelial growth was determined as the average diameter of the colony measured at two right angles. Each treatment included five replicates and a negative control containing unsupplemented media. Foa's mycelial growth inhibition was calculated using the following formula:

$$
\text { Growth inhibition }(\%)=\frac{(\mathrm{Dc}-\mathrm{Dt})}{\mathrm{Dc}} * 100
$$

\section{Where}

Dc: Diameter of colony in the control ( $\mathrm{mm})$

Dt: Diameter of colony in the treatment $(\mathrm{mm})$

\subsubsection{Sporulation inhibition assay}

The plates used to perform the mycelial growth inhibition assay were kept in incubation for 10 days under the same conditions to assess the effect of plant extracts on Foa sporulation according to the method described by Islam et al. [18]. For each colony, four discs $(5 \mathrm{~mm})$ taken along a diameter were transferred into a $1 \mathrm{~mL}$ tube of sterile distilled water. The tube was vortexed for $30 \mathrm{~s}$, and the spore concentration of the resulting suspension was determined using a Malassez Counting Chamber. Five counts per suspension were made.

\subsection{Antioxidant activity of plant extracts 2.4.1 Measurement of total phenolic compounds}

The total phenolic compounds (TPC) in each plant extract were quantified based on the method described by Bouhlali et al. [2]. Briefly, $100 \mu \mathrm{L}$ of plant filtrate was mixed with $500 \mu \mathrm{L}$ of $1 / 10$ water-diluted Folin-Ciocalteau's reagent. Subsequently, $400 \mu \mathrm{L}$ of sodium carbonate solution $(7.5 \% \mathrm{w} / \mathrm{v})$ was added. The mixture was left at room temperature for $60 \mathrm{~min}$, and its absorbance was measured at $765 \mathrm{~nm}$. Gallic acid at various concentrations (0 to $500 \mathrm{mg} / \mathrm{L}$ ) was used to construct the calibration curve and the results (means of four measurements) were expressed in mg of Gallic acid equivalents per $100 \mathrm{~g}$ dry weight (DW) of plant material (mg GAE/100 g DW).

\subsubsection{Measurement of flavonoid content}

The total flavonoid compounds (TFC) of plant material were measured according to the method previously described by Bouhlali et al. [19]. A sample of $500 \mu \mathrm{L}$ of plant extract was filled up to $2500 \mu \mathrm{L}$ using distilled water, mixed with $150 \mu \mathrm{L}$ of $5 \%$ sodium nitrite and $10 \%$ aluminum chloride, and incubated for $5 \mathrm{~min}$ at room temperature before adding $1 \mathrm{~mL}$ of $1 \mathrm{M}$ sodium hydroxide. The final volume of the mixture was made up to $5000 \mu \mathrm{L}$ using distilled water. A standard curve was constructed using rutin at various concentrations ranging from 0 to $800 \mathrm{mg} / \mathrm{L}$. The absorbance of the resulting solution was measured at $510 \mathrm{~nm}$ after homogenization. The results (means of four measurements) were expressed in milligram of rutin equivalents per $100 \mathrm{~g}$ DW of plant material (mg RE/100 g DW).

\subsubsection{Trolox equivalent antioxidant capacity (TEAC)}

The TEAC assay was performed using the method of Re et al. [20]. Aqueous solutions of both ABTS (2,2'-azinobis (3-ethylbenzothiazoline-6-sulfonic acid)) $(7 \mathrm{mM})$ and potassium persulphate $(2.45 \mathrm{mM})$ had been mixed and kept in dark at room temperature for 12-16 h to generate ABTS radical cations $\left(\mathrm{ABTS}^{+}\right)$. Subsequently, the absorbance of the mixture at $734 \mathrm{~nm}$ was adjusted to $0.700 \pm$ 0.005 by adding distilled water. Finally, $30 \mu \mathrm{L}$ of diluted plant filtrate was added to $3 \mathrm{~mL}$ of the diluted ABTS radical solution. The mixture was allowed to stand for $6 \mathrm{~min}$ at room temperature before the absorbance was measured at $734 \mathrm{~nm}$. Total antioxidant activity (mean of four measurements) was expressed in mmol of Trolox equivalents per $100 \mathrm{~g}$ DW (mmol TE/100 g DW) using an aqueous solution of Trolox as a standard curve. 


\subsubsection{Ferric-reducing antioxidant power assay (FRAP)}

Ferric-reducing ability of plant extracts was evaluated according to the method previously described by Benzie and Strain [21]. Briefly, $5 \mathrm{~mL}$ of TPTZ (2,4,6-tripyridyls-triazine) solution (10 mM TPTZ in $40 \mathrm{mM} \mathrm{HCl}), 50$ $\mathrm{mL}$ of acetate buffer ( $300 \mathrm{mM}, \mathrm{pH} 3.6)$, and $5 \mathrm{~mL}$ of $\mathrm{FeCl}_{3}(20 \mathrm{mM}$ in water solution) were mixed to prepare the FRAP reagent. For each sample, $10 \mu \mathrm{L}$ of plant filtrate was added to $2 \mathrm{~mL}$ of the FRAP reagent. The resulting solution was incubated at room temperature for $30 \mathrm{~min}$ before the absorbance at $593 \mathrm{~nm}$ was measured against a blank solution. Total antioxidant activity (mean of four measurements) was expressed in mmol of Trolox equivalents per $100 \mathrm{~g}$ DW (mmol TE/100 g DW) using an aqueous solution of Trolox as a standard curve.

\subsection{Statistical analysis}

Statistical analysis was performed using StatView 5.0 software. One-way analysis of variance (ANOVA) and post hoc Bonferroni tests were carried out to determine significant differences between plant extracts in respect to their antifungal activity, phenolic and flavonoid contents, and antioxidant property with $p<0.05$ as the significance level. In addition, Pearson's square correlation coefficient $\left(R^{2}\right)$ was calculated to measure pairwise associations among variables.

\section{Results}

\subsection{Evaluation of antifungal activity}

The plant extracts affected significantly $(p<0.05)$ and dose-dependently the pathogen's mycelial growth, spore germination, and sporulation. At every concentration, $E$. torquata had the greatest inhibitory effect on fungal mycelial growth followed by $C$. atlantica, $N$. oleander, $S$. molle, and A. cyanophylla (Fig. 1). In addition, higher plant extract's concentration induced more potent inhibition of the pathogen's growth, regardless of plant species, though the effect of $A$. cyanophylla extract at the lowest concentration (1\%) was not significant.

Moreover, for all plant extracts, except A. cyanophylla and $S$. mole at the lowest concentration, increased extract doses resulted in more intense inhibition of Foa's spore germination (Fig. 2). At the dose of 4\%, E. torquata extract induced the strongest spore inhibition (79.21\%), followed by C. atlantica (67.97\%) and N. oleander (50.56\%). The other extracts exhibited a weaker anti-germinative effect, ranging between $43.82 \%$ for $S$. molle and $16.85 \%$ for A. cyanophylla. However, A. cyanophylla extract at the concentrations of $1 \%$ and $2 \%$ had no significant effect on Foa's spore germination.

Finally, the same pattern of inhibition was observed in Foa's sporulation with the extracts of E. torquata and $C$. atlantica, causing the greatest sporulation reductions

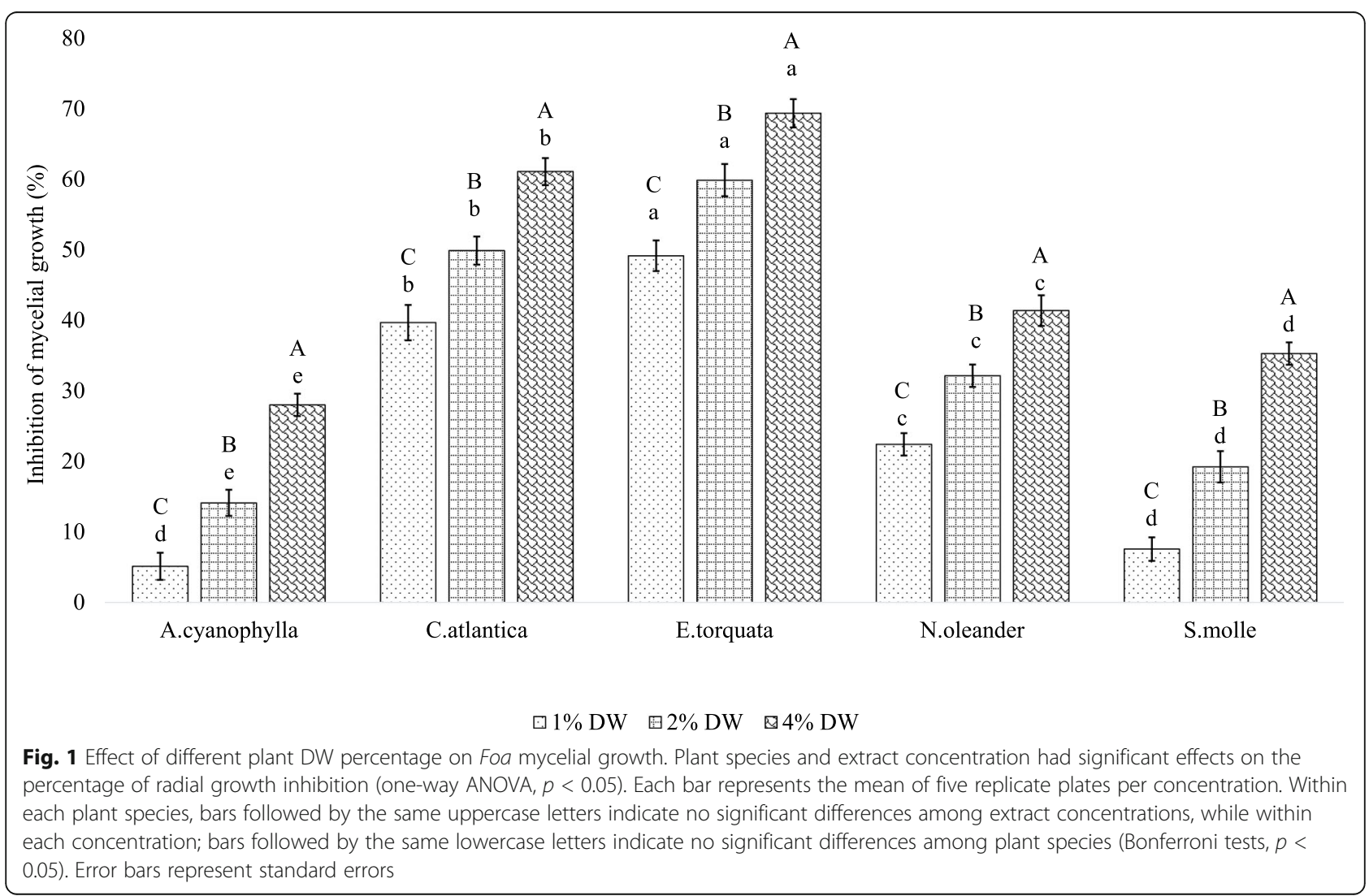




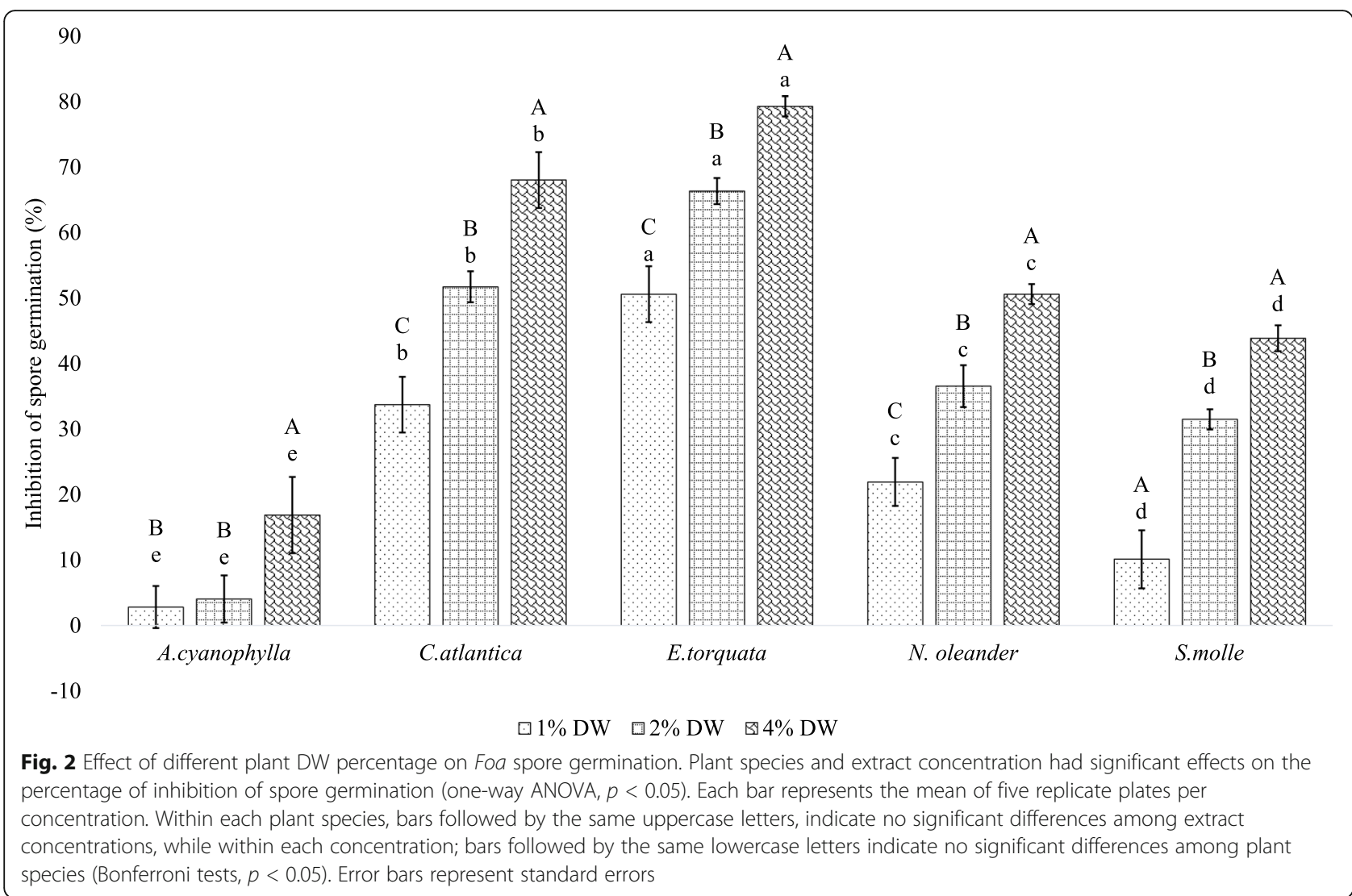

(44.97\% and $37.32 \%$ respectively at the concentration of $4 \%)$, followed by the extract of $N$. oleander that lowered Foa sporulation by $23.92 \%$ and $14.35 \%$ at the doses of $2 \%$ and $4 \%$ respectively (Fig. 3 ). In contrast, the extracts of $A$. cyanophylla and $S$. molle at the lowest concentration (1\%) fostered Foa sporulation respectively by $30.62 \%$ and $10.52 \%$. The extracts of $N$. oleander (at $1 \%$ ), A. cyanophylla (at 4\%), and S. molle (at 4\%) showed no significant effect on Foa sporulation.

\subsection{Total phenolic and flavonoid contents}

The plant extracts displayed significant differences $(p<$ $0.05)$ concerning their total polyphenols and flavonoids level (Fig. 4). Specifically, total phenolic content ranged between $7.348 \mathrm{~g}$ GAE/100 g DW in E. torquata and $1.536 \mathrm{~g}$ GAE/100 g DW in A. cyanophylla. Similarly, E. torquata had the greatest total flavonoids content (5.759 g RE/100 g DW), followed by C. atlantica, S. molle, A. cyanophylla, and $N$. oleander which showed the lowest concentration of flavonoids (0.986 g RE/100 g DW).

\subsection{Evaluation of antioxidant activity}

The antioxidant property of the studied plant extracts, as measured by both TEAC and FRAP assays, showed significant differences $(p<0.05)$ (Fig. 5) and strong correlations $\left(R^{2} \geq 0.974, p<0.01\right)$ with total phenolic and flavonoids contents (Table 1). TEAC values ranged between 7.47 and $38.97 \mathrm{mmol} \mathrm{TE} / 100 \mathrm{~g} \mathrm{DW}$ and were strongly correlated $\left(R^{2}=0.999, p<0.01\right)$ with those of FRAP which varied between 8.95 and $36.43 \mathrm{mmol} \mathrm{TE} / 100 \mathrm{~g}$ DW (Table 1). Finally, phenolics and flavonoids were found to be correlated with antifungal activity, especially mycelial growth inhibition $\left(R^{2} \geq 0.669, p<0.01\right)$ and spore germination inhibition of Foa $\left(R^{2} \geq 0.54, p<0.01\right)$ (Table 1$)$.

\section{Discussion}

Organic soil amendment contributes greatly to fostering plant biomass and health [22]. For example, the use of compost improves physico-chemical properties and structure of soil, enhances the diversity of microbial communities, and enriches potentially the taxa which play major role in suppressing various fungal and bacterial plant diseases [23]. In addition, the use of organic waste with biocidal effects in composting process can offer an additional way of increasing compost's impact on plant pathogens. Our work provides strong evidence that the extracts of some plants (trees and bushes) possess potent inhibitory effect on Foa. These plants produce a great deal of pruning biomass that can be utilized in the production of bioactive compost as a soil amendment for sustainable control of Bayoud in date palm groves. 

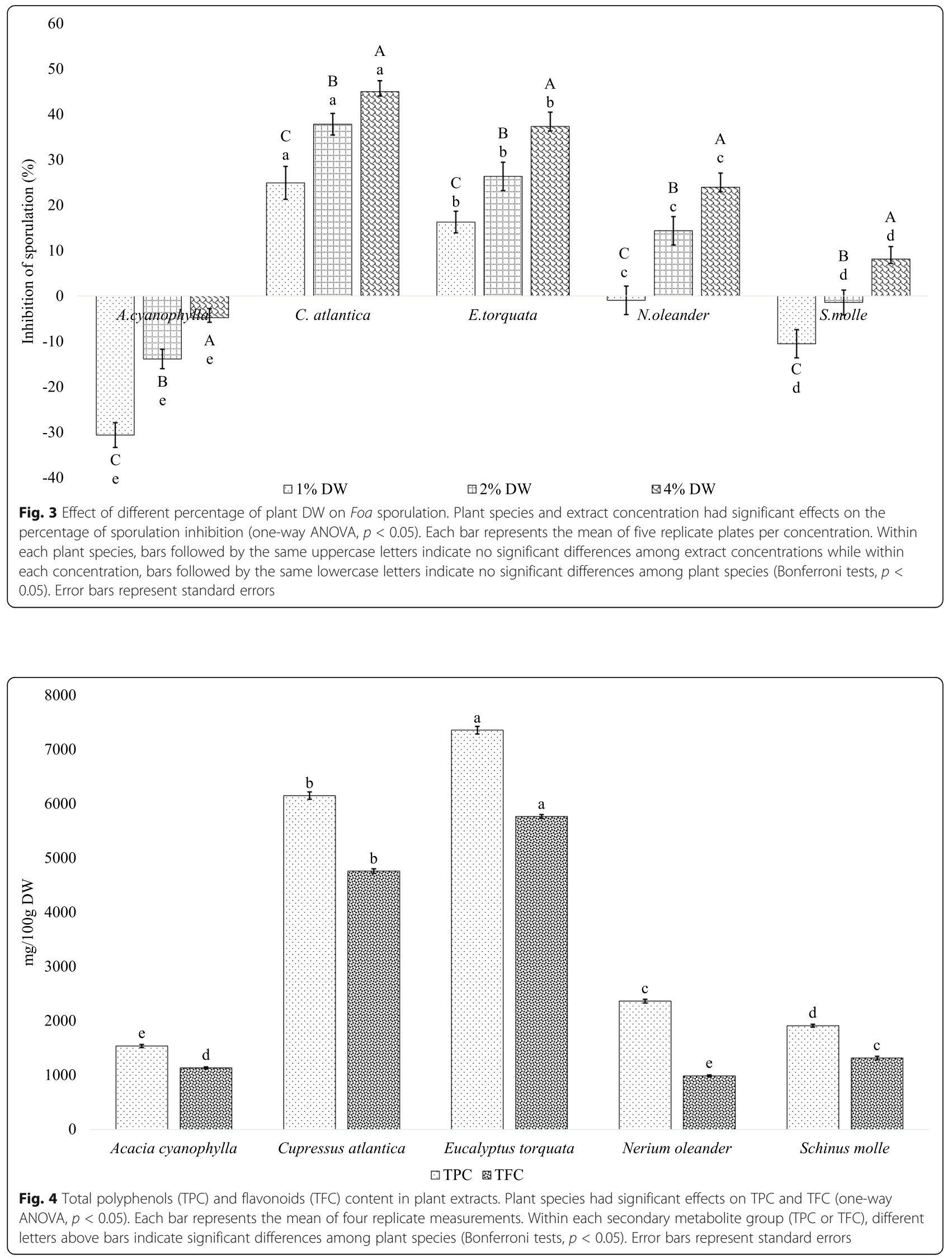


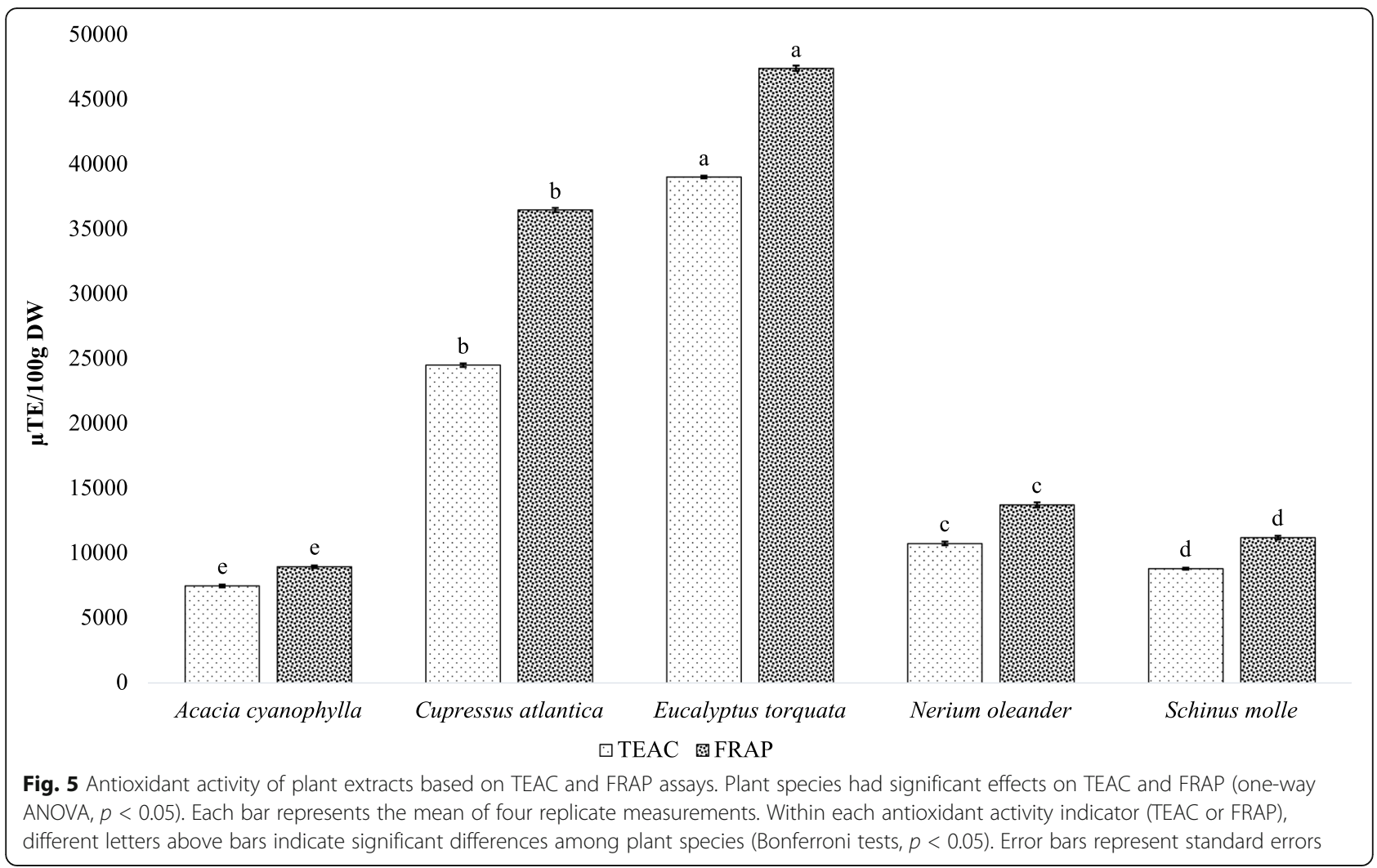

Bayoud is an incurable disease of date palm trees caused by Foa [24]. Its control is based on the combination of many approaches, including prophylactic measures, cultural practices, and intensive management of the pathogen's populations in order to prevent its growth and establishment. The use of natural biocidal products can reinforce this strategy. In this study, we demonstrate that the plants E. torquata and C. atlantica have strong antifungal activities, suggesting that their incorporation in compost may contribute to the management of Foa's community in soil. Specifically, the capacity of these plant extracts to decrease sporulation

Table 1 Correlation between polyphenols, flavonoids, antioxidant, and antifungal activities assays

\begin{tabular}{llllllll}
\hline & TPC & TFC & FRAP & TEAC & PRG & PISG & PSI \\
\hline TPC & 1 & & & & & & \\
TFC & $0.978^{* *}$ & 1 & & & & & \\
FRAP & $1^{* *}$ & $0.978^{* *}$ & 1 & & & & \\
TEAC & $0.999^{* *}$ & $0.974^{* *}$ & $0.999^{* *}$ & 1 & & & \\
PRGI & $0.719^{* *}$ & $0.669^{* *}$ & $0.731^{* *}$ & $0.724^{* *}$ & 1 & & \\
PISG & $0.606^{* *}$ & $0.54^{* *}$ & $0.622^{* *}$ & $0.616^{* *}$ & $0.925^{* *}$ & 1 & \\
PSI & $0.568^{* *}$ & $0.527^{* *}$ & $0.579^{* *}$ & $0.552^{* *}$ & $0.864^{* *}$ & $0.835^{* *}$ & 1 \\
\hline
\end{tabular}

TPC total phenolic content, TFC total flavonoid content, FRAP ferric-reducing antioxidant power, TEAC Trolox equivalent antioxidant capacity, PRGI percentage of radial growth inhibition, PISG percentage of inhibition of spore germination, PSI percentage of sporulation inhibition, ${ }^{* *} p<0.01$ and inhibit spore germination in the pathogen population can be detrimental to the onset of the disease and the spreading of fungal spores which are considered the primary inoculum for the infection of date palm by Foa. Additionally, the finding that E. torquata and C. atlantica filtrates affect strongly the pathogen's mycelial growth suggests that the use of these two bioactive plant species in compost can lead to a reduced saprophytic development of Foa and thus to a decreased soil infectious potential. In overall, our work laid the foundation for developing novel strategies to the control of Bayoud disease in palm groves based on the use of bioactive plant wastes.

A large body of work has reported that the essential oils and extracts drawn from some Eucalyptus species showed a dose dependent antifungal activity against seven Fusarium species, namely, F. oxysporum, F. solani, $F$. verticillioides, F. proliferatum, $F$. subglutinans, F. graminearum, and $F$. sporotrichioides [12, 25-27]. In addition, different species of the genus Cupressus had a strong antifungal effect against the mycelial growth of $F$. oxysporum, F. solani, F. culmorum, F. equisiti, F. verticillioides, F. nygamai, and F. subglutinans that was positively correlated with the applied dose [11, 28, 29]. There is a general consensus that the antifungal effect of plants might be associated with their content of secondary metabolites. Our results are in line with previous 
findings as plant antifungal activity was moderately to strongly correlated with phenolic and flavonoid contents $\left(R^{2} \geq 0.527\right)$ [30, 31]. In fact, $E$. torquata and C. atlantica that showed the greatest concentrations of polyphenols and flavonoids induced the strongest inhibition effects. In contrast, the relatively weaker inhibitory effects exhibited by the other plants may be attributed to low amounts and/or bio inactive composition of their secondary metabolites. These findings corroborate also with those reported by Daayf et al. [32] who found a significant increase in the synthesis of phenolic compounds by date palm-resistant and susceptible cultivars following infection by Foa, indicating a possible role of phenolic compounds in the inactivation of the pathogen upon infection.

Diverse mechanisms can underlie fungal toxicity of plant secondary metabolites including the inhibition of enzymes by oxidized compounds, probably by reactions with sulfhydryl groups or by less specific interactions with proteins, interference with cell wall synthesis, alteration of cell permeability, interference with electron transport, absorption of nutrients, adenosine triphosphatase, and other cell metabolic pathways [33-35]. Bioactive compounds found in plant extracts may act simultaneously or separately, their modes of action can be similar or different, and their targets include metabolic pathways involved in mycelial growth, sporulation, and spore germination, which result in effective antifungal activity [36].

Moderate to strong correlations $\left(R^{2} \geq 0.552, p<0.01\right)$ were also found between antioxidant activity and the inhibition of fungal growth, spore germination, and sporulation. As a matter of fact, antioxidants have been reported to play a major role in increasing treatment effectiveness against plant fungal pathogens when combined as adjuvants with fungicides [37]. Their effect may be due to increased fungal cell permeability that subsequently allows greater fungicide diffusion into cells or to reduced intracellular fungicide oxidation that results in stronger fungitoxicity $[38,39]$. In agreement with these investigations, our results suggest that the antifungal properties of plant extracts coupled with their antioxidant activity are responsible for potent inhibitory effect against the causal agent of the Bayoud disease (Foa).

Regardless of their mechanisms of action, the present work demonstrated that extracts from E. torquata and $C$. atlantica impede the mycelial growth, spore production, and spore germination of Foa under controlled laboratory conditions. However, because of the lack of field data, the use of these plants in an integrated strategy for Bayoud management requires further research. Specifically, related future investigations must address the effect of raw plant material in compost on the pathogen, microbial community, and structure, especially beneficial taxa, physical, and chemical properties of soil, as well as date palm growth and development.

\section{Conclusion}

Taken together, our data showed that extracts from $E$. torquata and $C$. atlantica waste produced during trimming of green urban spaces have a strong antifungal activity against Foa. The use of these plants as composted material may offer a better alternative to costly and environmentally unfriendly fungicides. Studies are underway with the objective of developing and implementing a compost-based biological approach to control Bayoud disease in Moroccan date palm groves. Further studies are recommended to evaluate the stability of antifungal effect retained by these plant species after composting process.

\section{Abbreviations \\ TEAC: Trolox equivalent antioxidant capacity; FRAP: Ferric-reducing antioxidant power; TPTZ: 2,4,6-tripyridyl-s-triazine; TE: Trolox equivalent; DW: Dry weight; GAE: Gallic acid equivalent; RE: Rutin equivalent; Foa: Fusarium oxysporum f. sp. Albedinis; TPC: Total phenolic content; TFC: Total flavonoids content; PRGI: Percentage of radial growth inhibition; PISG: Percentage of inhibition of spore germination; PSI: Percentage of sporulation inhibition}

\section{Acknowledgements}

We would like to thank Dr. Homrani Bakali, for the identification of plant species, and Dr. Bammou and Dr. Sellam for their valuable suggestions for the accomplishment of this research work.

\section{Authors' contributions}

E.D.T.B., A.E., and R.M. conceived the presented idea. A. E and R. M verified the analytical methods and supervised the findings of this work. E.D.T.B., M.D., and H.B. carried out the experiment. E.D.T.B, M.D., and A.E. wrote the manuscript after discussion of the results with all authors. All authors have read and approved the manuscript for submission.

\section{Funding}

The authors received no specific funding for this work.

Availability of data and materials

The available data is included in the manuscript.

Ethics approval and consent to participate

Not applicable

Consent for publication

Not applicable

\section{Competing interests}

None

\section{Author details}

${ }^{1}$ National Institute for Agricultural Research, Regional Center of Errachidia, Errachidia, Morocco. ${ }^{2}$ Biochemistry of Natural Products, Faculty of Sciences and Techniques, Moulay Ismail University, 52000 Errachidia, Morocco.

Received: 1 May 2020 Accepted: 3 August 2020

Published online: 10 November 2020

\section{References}

1. Bouhlali EDT, El Hilaly J, Ennassir J, Benlyas M, Alem C, Amarouch MY, FilaliZegzouti Y (2018) Anti-inflammatory properties and phenolic profile of six Moroccan date fruit (Phoenix dactylifera L.) varieties. J King Saud Univ Sci 30(2018):519-526 https://doi.org/10.1016/j.jksus.2017.08.011

2. Bouhlali EDT, Ramchoun M, Alem C, Ghafoor K, Ennassir J, Zegzouti YF (2017) Functional composition and antioxidant activities of eight Moroccan date fruit varieties (Phoenix dactylifera L.). J Saudi Soc Agric Sci 16(3):257264 https://doi.org/10.1016/j.jssas.2015.08.005 
3. Moroccan ministry of agriculture and fisheries (2015). Investor's guide in the agricultural sector in Morocco. Available online. http://www.fruitrop.com/ en/content/download/33851/540304/version/12/file/. Accessed 8 Jun 2020.

4. Essarioui A, Sedra MH (2017) Lutte contre la maladie du bayoud par solarisation et fumigation du sol : Une expérimentation dans les palmeraies du Maroc. Cah Agric 26(4):45010 https://doi.org/10.1051/cagri/2017043

5. Essarioui A, Ben-Amar H, Khoulassa S, Meziani R, Amamou A, Mokrini F (2018) Gestion du bayoud du palmier dattier dans les oasis marocaines. Rev Mar Sci Agro 6(4):537-543

6. Sedra, H. (2012). Date palm farmer guide: implementation and management of date palm orchards. INRA, Morocco. Paper cover, 311 p. In French (Guide du Phoeniciculteur: Mise en place et conduite des vergers phoénicicoles), ISBN/IPC: 978-9954-8602-8-1.

7. El Modafar C (2010) Mechanisms of date palm resistance to Bayoud disease: current state of knowledge and research prospects. Physiol Mol Plant P 74(5-6):287-294 https://doi.org/10.1016/j.pmpp.2010.06.008

8. Parween D, Sahu BB, Kumari M, Pudake RN (2019) Plant metabolites involved in plant-pathogen Interactions. In: Varma A, Tripathi S, Prasad R (eds) Plant biotic interactions. Springer, Cham https://doi.org/10.1007/978-3030-26657-8_5

9. Mujeeb F, Bajpai P, Pathak N (2014) Phytochemical evaluation, antimicrobial activity, and determination of bioactive components from leaves of Aegle marmelos. Biomed Res Int 2014:497606 https://doi.org/10.1155/2014/497606

10. Mezouari A, Makhloufi A, Bendjima K, Benlarbi L, Boulanouar A, Makhloufi K, Gonzalez MJ (2019) Antifungal activity of Acacia tortilis subsp. raddiana tar on Fusarium oxysporum f. sp. albedinis, the cause of bayoud disease of the date palm in Southwest Algeria. Indian J Agric Sci 53(6):713-717 https://doi. org/10.18805/IJARe.A-417

11. Saad AM, Mohammed MM, Ghareeb MA, Ahmed WS, Farid MA (2017) Chemical composition and antimicrobial activity of the essential oil of the leaves of Cupressus macrocarpa Hartweg. Ex Gordon J Appl Pharm Sci 7(9): 207-212 https://doi.org/10.7324/JAPS.2017.70928

12. Gakuubi, M. M., Maina, A. W., \& Wagacha, J. M. (2017). Antifungal activity of essential oil of Eucalyptus camaldulensis dehnh. against selected Fusarium spp. Int. J. Microbiol. ID 8761610. https://doi.org/10.1155/2017/8761610.

13. Hadizadeh I, Peivastegan B, Kolahi M (2009) Antifungal activity of nettle (Urtica dioica L.), colocynth (Citrullus colocynthis L. Schrad), oleander (Nerium oleander L.) and konar (Ziziphus spina-christi L.) extracts on plants pathogenic fungi. Pak J Biol Sci 12(1):58 https://doi.org/10.3923/pjbs.2009.58. 63

14. López-Meneses AK, Plascencia-Jatomea M, Lizardi-Mendoza J, Rosas-Burgos EC, Luque-Alcaraz AG, Cortez-Rocha MO (2015) Antifungal and antimycotoxigenic activity of essential oils from Eucalyptus globulus, Thymus capitatus and Schinus molle. Food Sci Technol Res 35(4):664-671 https://doi. org/10.1590/1678-457X.6732

15. Hmidani A, Bouhlali EDT, Khouya T, Ramchoun M, Filali-zegzouti Y, Benlyas M, Alem C (2019) Effect of extraction methods on antioxidant and anticoagulant activities of Thymus atlanticus aerial part. Scientific African 7: e00143 https://doi.org/10.1016/j.sciaf.2019.e00143

16. Bammou M, Sellam K, Jaiti F, El-Rhaffari L, Echchagadda G, Ibijbijen J, Nassiri $L$ (2015) Ethnopharmacological study and antifungal activity of three plants (Asteraceae Family) from. Asian. J Appl Sci 3(4):13-24

17. Sellam K, Bammou M, Ramchoun M, Bouhlali EDT, Jaiti F, Nassiri L, ElRhaffari $L$ (2015) Antifungal potential of the Seed and Leaf Foeniculum vulgare Mill essential oil in liquid and vapor phase against phytopathogenic fungi. J Appl Pharm Sci 5(11):50-54 https://doi.org/https://doi.org/10.7324/ JAPS.2015.501108

18. Islam MR, Alam S, Rahman MZ, Chowdhury SP, Begum MF, Akhter N, Alam MS, Han KD, Lee MW (2003) Effects of plant extracts on conidial germination, mycelial growth and sporulation of fungi isolated from poultry feed. Mycobiology 31(4):221-225 https://doi.org/10.4489/MYCO.2003.31.4. 221

19. Bouhlali EDT, Bammou M, Sellam K, Benlyas M, Alem C, Filali-Zegzouti Y (2016) Evaluation of antioxidant, antihemolytic and antibacterial potential of six Moroccan date fruit (Phoenix dactylifera L.) varieties. J King Saud Univ Sci 28(2):136-142 https://doi.org/10.1016/j.jksus.2016.01.002

20. Re R, Pellegrini N, Proteggente A, Pannala A, Yang M, Rice-Evans C (1999) Antioxidant activity applying an improved ABTS radical cation decolorization assay. Free Radical Bio Med 26(9-10):1231-1237 https://doi. org/10.1016/S0891-5849(98)00315-3
21. Benzie IF, Strain JJ (1999) Ferric reducing/antioxidant power assay: direct measure of total antioxidant activity of biological fluids and modified version for simultaneous measurement of total antioxidant power and ascorbic acid concentration. Methods Enzymol 299:15-27 https://doi.org/10. 1016/S0076-6879(99)99005-5

22. Bonilla N, Gutiérrez-Barranquero J, Vicente A, Cazorla F (2012) Enhancing soil quality and plant health through suppressive organic amendments. Diversity 4(4):475-491 https://doi.org/10.3390/d4040475

23. Martin (2014) Potential of compost tea for suppressing plant diseases. CAB Reviews 9(32):1-38 https://doi.org/10.1079/PAVSNNR20149032

24. Oubraim S, Sedra MH, Lazrek HB (2016) A relationship between bayoud disease severity and toxin susceptibility of date palm cultivars. Emir J Food Agr 28(1):45-51 https://doi.org/10.9755/ejfa.2016-01-084

25. Elgorban AM, Bahkali AH, El-Metwally MA, Elsheshtawi M, Abdel-Wahab MA (2015) In vitro antifungal activity of some plant essential oils. Int J Pharm 11(1):56-61 https://doi.org/10.3923/ijp.2015.56.61

26. Sharma A, Rajendran S, Srivastava A, Sharma S, Kundu B (2017) Antifungal activities of selected essential oils against Fusarium oxysporum f. sp. lycopersici 1322, with emphasis on Syzygium aromaticum essential oil. J Biosci Bioeng 123(3):308-313 https://doi.org/10.1016/j.jbiosc.2016.09.011

27. Fradi AJ, Al-Araji AM (2015) Effect of Eucalyptus Camaldulensis terpens, alkaloids and phenols against Fusarium oxysporum. Iraqi J Sci 56(4A):28072810

28. Amri I, Hanana M, Gargouri S, Jamoussi B, Hamrouni L (2013) Comparative study of two coniferous species (Pinus pinaster Aiton and Cupressus sempervirens L. var. dupreziana [A. Camus] Silba) essential oils: chemical composition and biological activity. Chil J Agric Res 73(3):259-266 https:// doi.org/10.4067/S0718-58392013000300008

29. Al-Snafi AE (2016) Medical importance of Cupressus sempervirens-A review. IOSR J Pharm 6(6):66-76

30. Mahmoudi S, Khali M, Benkhaled A, Benamirouche K, Baiti I (2016) Phenolic and flavonoid contents, antioxidant and antimicrobial activities of leaf extracts from ten Algerian Ficus carica L. varieties. Asian Pac J Trop Biomed 6(3):239-245 https://doi.org/10.1016/j.apjtb.2015.12.010

31. Chen C, Peng X, Chen J, Wan C (2020) Antioxidant, antifungal activities of ethnobotanical Ficus hirta Vahl. and analysis of main constituents by HPLCMS. Biomedicines 8(1):15 https://doi.org/10.3390/biomedicines8010015

32. Daayf F, El Bellaj M, El Hassni M, J'aiti F, El Hadrami I (2003) Elicitation of soluble phenolics in date palm (Phoenix dactylifera) callus by Fusarium oxysporum f. sp. albedinis culture medium. Environ Exp Bot 49(1):41-47 https://doi.org/10.1016/S0098-8472(02)00048-5

33. Cowan MM (1999) Plant products as antimicrobial agents. Clin Microbiol Rev 12(4):564-582 https://doi.org/10.1128/CMR.12.4.564

34. Mohammedi Z, Atik F (2013) Fungitoxic effect of natural extracts on mycelial growth, spore germination and aflatoxin B1 production of Aspergillus flavus. Aust J Crop Sci 7(3):293-298

35. Othman L, Sleiman A, Abdel-Massih RM (2019) Antimicrobial activity of polyphenols and alkaloids in Middle Eastern plants. Front Microbiol 10(911) https://doi.org/10.3389/fmicb.2019.00911

36. Jiménez-Reyesa MF, Carrascob H, Oleab AF, Silva-Morenoa E (2019) Natural compounds: a sustainable alternative to the phytopathogens control. J Chil Chem Soc 64(2):4459-4465 https://doi.org/10.4067/S071797072019000204459

37. Shomeet AM, El-Samadisy AM, El-Kholy RM, Ibrahim IS (2018) Effect of fungicides, antioxidants and their mixtures on mycelial growth of some fungi. Sciences 8(02):647-655

38. Simonetti G, Villa A, Simonetti N (2002) Enhanced contact activity of fluconazole in association with antioxidants against fluconazole-resistant organisms. J Antimicrob Chemother 50(2):257-259 https://doi.org/10.1093/ $\mathrm{jac} / \mathrm{dkf102}$

39. Ali, W.M.S.A., 2008. Integrated control of some tomato diseases. Ph.D. Thesis, Fac. of Agric., (Cairo) Al-Azhar Univ., p 239

\section{Publisher's Note}

Springer Nature remains neutral with regard to jurisdictional claims in published maps and institutional affiliations. 